Rev 2007;(2):MR000005.

2. Pica N, Bourgeois F. Discontinuation and nonpublication of randomized clinical trials conducted in children. Pediatrics 2016;138(3):e20160223.

3. De Angelis CD, Drazen JM, Frizelle FA, et al. Clinical trial registration: a statement from the International Committee of Medical Journal Editors. JAMA 2004;292(11):1363-4.

4. Dal-RéR, IoannidisJP, Bracken MB, etal. Making prospective registration of observational research a reality. Sci Transl
Med 2014;6(224):224cm1.

5. Kasenda B, VonElmE, You J, etal.Prevalence, characteristics, and publication of discontinued randomized trials. JAMA 2014;311(10):1045-51.

6. Kasenda B, Von Elm EB, You J, et al. Learning from failure-rationale and design for a study about discontinuation of randomized trials (DISCO study). BMC Med Res Methodol 2012;12:131.

\title{
The principle of synchronicity-equivalence and chronomedicine: relevance and methodological exploration
}

\section{INTRODUCTION}

More than half a century ago, Carl Jung and Wolfgang Pauli developed a revolutionary hypothesis: natural phenomena are ruled not only by the principle of causality, but also by a kind of natural order that interconnects and regulates all events. Jung designated it as "principle of synchronicity or equivalence" (SE), according to whether or not it was perceived by the human mind. ${ }^{1}$ Currently, the effect of the principle of SE on the natural world is known as "chronobiology". The effect of the principle of SE on health and disease processes is known as "chronomedicine". Modern research methods allow for the identification of organization patterns that, in spite of their importance, usually go unnoticed by the human mind.

This paper briefly describes the origin, evolution and significance of the concept of SE in modern medicine. ${ }^{2,3}$

\section{Causality: the familiar principle}

Causality consists of a successive series of events in which the precedent (cause) gives rise to the subsequent (effect), within the confines of time, space and formal logic. ${ }^{1,2}$ However, causality is actually a habit of the mind, born from a repeated historical precedent originating an abstraction (bias). This abstraction results from a mixture of habits, beliefs and common sense, since every phenomenon does not stem from a single cause, but from a network of causes that our lack of subtlety prevents us from perceiving in its entirety. ${ }^{2}$ Therefore, causality is only applicable to certain portions of reality, and not to reality as a whole or unicity; from this latter perspective, everything is, to a certain extent, the cause of everything (unus mundus). ${ }^{2}$

\section{Synchronicity-equivalence: the new principle}

Synchronicity consists in the detection, by the human mind, of a meaningful and a causal coincidence between two or more events in the world. For this reason, this principle is also known as the "meaningful coincidence" or "a causal connection", because the relationship established between the events in question is not cause-effect nor random; their relation exceeds the likelihood to be attributed to chance. ${ }^{1}$ Beyond the significance of synchronicity as a psychological phenomenon, ${ }^{4}$ that is, as the intuitive capacity of the human mind to perceive the relation between two events significantly but not causally related, its value is based on evidencing the existence of a principle of nature. ${ }^{5}$

The perception of this connection is not an invention of the mind, but the brief and intuitive perception of the triggering of a natural pattern that overlays, at that moment, several phenomena. These are oscillatory patterns which -even though omnipresent-, usually go unnoticed to a human being, who can only catch glimpses of them (synchronic episodes). Therefore, Jung established a difference between the existence of organization patterns regardless of their perception by man: the principle of equivalence (Gleichartigkeit); and the perception of patterns by the human mind: principle of synchronicity (Sinngemässe Koinzidenz). ${ }^{5}$

It has been proposed that the perception of these patterns (equivalence) in a conscious fashion (synchronicity) would be possible thanks to the presence of certain reflexes located in areas that are phylogenetically old in the central nervous system (autonomous-reptilian nervous system). These areas are responsible for aligning (consciously or unconsciously) the body to world rhythms. This would explain the existence of synchronic events in human beings, as well as the collective coordinated behaviors of several living creatures, both among them and in compass with the cycles of Earth. ${ }^{1,4,6,7}$ 
It is important to point out that Arthur Schopenhauer had already hinted at the influence of the coordinated action of two natural forces (causality and SE) in the development of world events. He stated that, metaphorically, it resembled the geographical locations that originated from the intersection of parallels and meridians. ${ }^{1}$ From this perspective, phenomena are subjected to a causal generative order (linearity), which would be deployed under the influence of a cyclic pattern affecting the time and space in question (complexity-recursiveness). ${ }^{1,2,6,8}$

\section{The principle of synchronicity-equivalence and chronobiology}

The universe is affected by rhythms and cycles, which -together with gravity and the chemical composition of the Earth's atmosphere- have guided the evolution of life. Some of these rhythms (exogenous clocks) have managed to induce endogenous rhythms (biological clocks) inside the body, which contributed to the adaptation to the environment. This phenomenon is known as "chronobiology". Endogenous rhythms emerged, based on the duration of the day (20-28 hours) or circadian rhythms, longer than 20 hours (ultradian) or shorter than 28 hours (infradian). ${ }^{9}$

The human body follows at least 180 rhythms, with its biological clocks located in the central nervous system (suprachiasmatic, hypothalamic nuclei, etc.), as well as in organs (liver, heart, lung, etc.). Nevertheless, the existence of cycles whose rhythms may last decades or centuries cannot be ruled out. These cycles are not supported by internal clocks and are hard to identify. They may have a significant impact on body functions (chronophysiology), the development of disease (chronopathology) and the response to therapeutic interventions (chronopharmacology). ${ }^{9}$

\section{Chronomedicine and its methodological exploration}

Data mining would be the perfect tool to search for these hidden organization patterns. It mainly deals with the detection of patterns underlying data sets. These patterns reveal associations that would otherwise remain hidden, but which become evident if an interpreter manages to assign an interpretation to them (meaningful coincidence). They can only be considered as causal when documented by other statistical methods. While this procedure includes implicit hypotheses -for example, during the selection of the dataset to be explored- these are not explained a priori. Data mining, at most, would reveal an interesting pattern of data, which is useful only if found to be meaningful. ${ }^{10}$

\section{CONCLUSION}

The SE would be a general principle of nature, complementary to causality, and able to assign cyclic organization patterns to world phenomena. This principle would be involved in the existence of physiological rhythms (chronobiology) and pathophysiological rhythms (chronopathology). The conscious and transient perception of their existence is known as synchronic event, but the difficulty in their perception requires the use of adequate methods to detect patterns, as is the case of data mining. It is therefore crucial to achieve a better understanding of the features and dynamics of this principle, so as to fully assess its influence on health, disease and therapeutic interventions.

Carlos G. Musso, M.D. ${ }^{a}$, Francisco Baez, student ${ }^{a}$, María J. Elias, student ${ }^{a}$, and Mónica Schpilberg, M.D. ${ }^{b}$

a. Department of Physiology, Instituto Universitario del Hospital Italiano de Buenos Aires, Argentina.

b. Department of Research, Hospital Italiano de Buenos Aires, Argentina.

http:/ / dx.doi.org/10.5546/ aap.2017.eng.309

To cite: Musso CG, Baez F, Elias MJ,et al. The principle of synchronicityequivalence and chronomedicine: relevance and methodological exploration. Arch Argent Pediatr 2017;115(4):309-310.

\section{REFERENCES}

1. Jung CG. Sincronicidad. Málaga: Sirio, 1988.

2. Peat FD. Sincronicidad. Puente entre mente y materia. Barcelona: Kairós, 1988

3. Verene DP. Coincidence, historical repetition, and selfknowledge: Jung, Vico, and Joyce. J Anal Psychol 2002; 47(3):459-78.

4. Yiassemides A. Chronos in synchronicity: manifestations of the psychoid reality. J Anal Psychol 2011;56(4):451-70.

5. GiegerichW.A seriousmisunderstanding: synchronicity and the generation of meaning. J Anal Psychol 2012;57(4):500-11.

6. Combray J. Synchronicity. Nature and Psyche in an Interconnected Universe. Texas: A\&M University Press, 2009.

7. Slater VE. Modern physics, synchronicity and intuition. Holist Nurs Pract 1992;6(4):20-5.

8. Musso CG, Bezic J, Christiansen S, et al. Histological glomerular patterns as chaotic attractors. Electron J Biomed 2007;1:21-7.

9. Tamargo J, Barberá J. Cronobiología, farmacología y patología. Barcelona: May 2005.

10. Dawson-Saunders B, Trapp R. Bioestadística médica. México: Manual Moderno, 1993:51-2. 